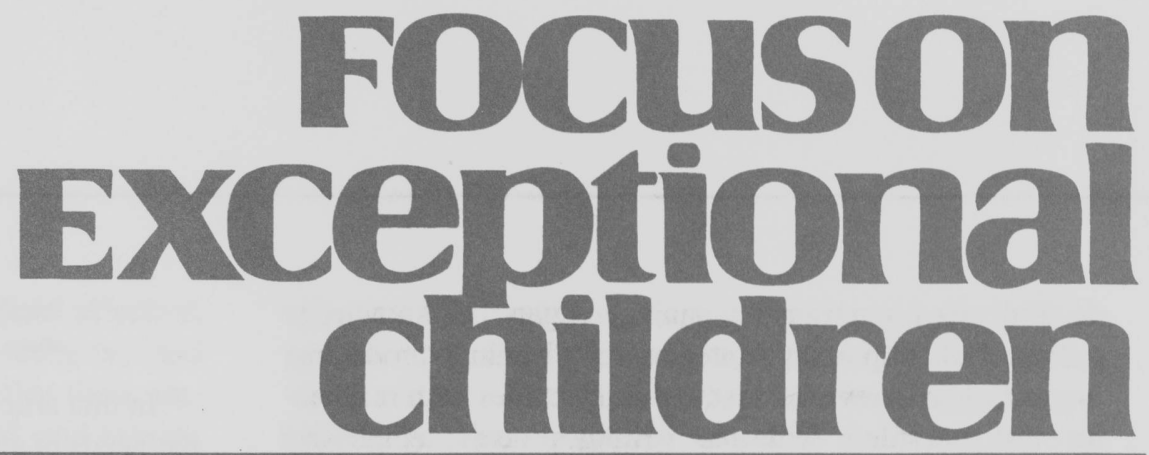

\title{
Self-Regulated Strategy Development in the Classroom: Part of a Balanced Approach to Writing Instruction for Students With Disabilities
}

\author{
Karen R. Harris, Steve Graham, and Linda H. Mason
}

Writing is a highly complex process; the writer not only must negotiate the rules and mechanics of writing, but also must maintain a focus on important aspects of writing such as organization, form and features, purposes and goals, audience needs and perspectives, and evaluation of the communication between author and reader (Bereiter \& Scardamalia, 1982; Scheid, 1991). In addition, writing requires extensive self-regulation and attention control (Graham \& Harris, 1994, 1996, 2000). For skilled writers, writing is a flexible, goal-directed activity that is scaffolded by a rich knowledge of cognitive processes and strategies for planning, text production, and revision. Skilled writers engage in purposeful and active self-direction of these processes and strategies (Harris, Schmidt, \& Graham, 1998). In fact, monitoring and directing one's own composing processes are crucial to the development of writing ability (Flower \& Hayes, 1980).

Learning to write is difficult and demanding. National and state writing assessments indicate that we are not yet highly effective at developing this critical competency among our students, as the majority of children in American schools demonstrates significant difficulties with narrative, expository, and persuasive writing (Applebee, Langer, Mullis, Latham, \& Gentile, 1994; Applebee, Langer, Jenkins, Mullis, \& Foertsch, 1990). In addition, children in our schools frequently demonstrate a deteriorating attitude toward writing, even though most children begin school with a positive attitude toward composing (Applebee, Langer, \& Mullis, 1986). Scardamalia and Bereiter (1986) have identified five areas of writing competence that are particularly difficult for the general school population: (a) generating content, (b) creating an organized structure for compositions, (c) formulating goals and higher level plans, (d) quickly and efficiently executing the mechanical aspects of writing, and (e) revising text and reformulating goals.

Researchers have found that students with learning disabilities (LD) or other special needs frequently have greater difficulty with writing than their normally achieving peers (Graham, Harris, \& Larsen, 2001; Harris \& Graham, 1992, 1999). Generally, students with learning problems produce writing that is less polished, expansive, coherent, and effective than students without learning disabilities (for greater details on the research base, see Graham \& Harris, 2002). Research indicates that students with learning disabilities lack critical knowledge of the writing process; have difficulty generating ideas and selecting topics;

Karen R. Harris and Steve Graham are with the University of Maryland. Linda H. Mason is with the University of Illinois, Champaign-Urbana. 
do little to no advance planning; engage in knowledge telling; lack important strategies for planning, producing, organizing, and revising text; have difficulties with mechanics that interferes with the writing process; emphasize mechanics over content when making revisions; and frequently overestimate their writing abilities.

For more than 20 years, Graham, Harris, and their colleagues have been involved in the development and evaluation of an instructional approach to developing writing and selfregulation strategies among students with significant writing problems. This approach is referred to as Self-Regulated Strategy Development (SRSD). SRSD has been used in several academic areas, including math and reading (see Wong, Harris, Graham, \& Butler, 2003), but in the area of writing the major goals of SRSD are threefold (Harris, Schmidt, \& Graham, 1998):

1. Assist students in developing knowledge about writing and powerful skills and strategies involved in the writing process, including planning, writing, revising, and editing.

2. Support students in the ongoing development of the abilities needed to monitor and manage their own writing.

\section{Exceptiona children}

ISSN 0015-511X FOCUS ON EXCEPTIONAL CHILDREN (USPS 203-360) is published monthly except June, July, and August as a service to teachers, special educators, curriculum specialists, administrators, and those concerned with the special education of exceptional children. This publication is annotated and indexed by the ERIC Clearinghouse on Handicapped and Gifted children for publication in the monthly Current Index to Journals in Education (CIJE) and the quarterly index, Exceptional Children Education Resources (ECER). The full text of Focus on Exceptional Children is also available in the electronic versions of the Education Index. It is also available in microfilm from Xerox University Microfilms, Ann Arbor, MI. Subscription rates: Individual, \$36 per year; institutions, $\$ 48$ per year. Copyright (C) 2003, Love Publishing Company. All rights reserved. Reproduction in whole or part without written permission is prohibited. Printed in the United States of America. Periodical postage is paid at Denver, Colorado. POSTMASTER: Send address changes to:

$$
\begin{gathered}
\text { Love Publishing Company } \\
\text { Executive and Editorial Office } \\
\text { P.O. Box } 22353 \\
\text { Denver, Colorado } 80222 \\
\text { Telephone (303) 221-7333 }
\end{gathered}
$$

Karen Harris

University of Maryland
Thomas Skrtic University of Kansas

James Shriner

University of Illinois

Erica J. Lawrence Editor
Stanley F. Love

Publisher
3. Promote children's development of positive attitudes about writing and themselves as writers (p. 134).

In this article, we discuss why SRSD is a good match to the needs of students with LD and others who struggle with writing, how SRSD is done in the classroom, how teachers can plan for and evaluate SRSD, and tips for getting started with this approach in the classroom. We also offer an example of SRSD instruction in an elementary classroom in which we have been working, illustrated with the performance of two of our students.

\section{SRSD AND STUDENTS WITH SEVERE LEARNING PROBLEMS}

While students with learning and behavioral problems are a heterogeneous group, research indicates that one commonality among these students is that the significant difficulties they face often arise from multiple problems of an affective, behavioral, and cognitive nature (Harris, 1982; Harris \& Graham, 1992, 1996a; Harris, Graham, \& Deshler, 1998). Ecological variables, including the situational, educational, cultural, and community networks the student is part of, are also critical concerns (Harris, 1982). As researchers have noted for some time, the transactional relationships among affect, behavior, cognition, and social and ecological variables need to be carefully considered (Harris, 1982; Kendall \& Braswell, 1982).

Many students with LD have difficulty with self-regulation, including the self-regulation of organized, strategic behaviors (Graham, Harris, \& Reid, 1992; Harris, 1986). They might have difficulty comprehending task demands, producing effective task strategies, and using strategies to mediate performance (Harris \& Graham, 1992). Some might lack or fail to make use of effective verbal mediation processes or might not have developed an effective linguistic control system, and thus experience difficulties using verbalizations (often referred to as self-speech) to guide behavior. Many of these students also experience reciprocal relationships among academic failure, self-doubts, learned helplessness, maladaptive attributions, unrealistic pretask expectancies, low self-efficacy, and low motivation. Impulsivity, difficulties with memory or other aspects of information processing, low task engagement and persistence, devaluation of learning, and low productivity are also among the problems these students and their teachers might need to deal with.

\section{SRSD: UNDERLYING PREMISES}

Harris and Graham began development of the SRSD approach to instruction with the underlying premise that students who face significant and often debilitating difficulties would benefit from an integrated approach to instruction 
that deliberately and directly addresses their affective, behavioral, and cognitive characteristics, strengths, and needs (Harris, 1982). Further, they asserted that these students often require more extensive, structured, and explicit instruction than their peers to develop skills, strategies (including academic, social, and self-regulation strategies), and understandings. The level of explicitness of instruction should be adjusted to meet student needs (Harris \& Graham, 1996b). This perspective requires that the same academic and self-regulation strategies are not necessarily targeted for all students, and that instructional components and processes need to be individualized. SRSD research indicates that as students' learning and behavioral challenges become more significant, strategy and self-regulation development becomes more complex and explicit, involving multiple learning tasks, components, and stages (Sawyer, Graham, \& Harris, 1992; Sexton, Harris, \& Graham, 1998).

Another premise evident from the beginning of Harris and Graham's work on SRSD was the need to integrate multiple lines of research from multiple theoretical perspectives in order to develop powerful interventions for students who face significant academic challenges (Harris, 1982; Harris \& Alexander, 1998: Harris \& Graham, 1985). Thus, SRSD has been, and continues to be, informed by research in areas such as development and characteristics of written language, expertise in written language among both children and adults, emerging practices in writing instruction, self-regulation, learning characteristics of students with significant learning problems, and effective teaching and learning. A thoughtful, effective integration of diverse, validated approaches to learning, regardless of whether the disciplines from which they originated are viewed as discordant (such as affective, behavioral, and cognitive approaches to teaching and learning), has been key to the development of SRSD.

\section{SRSD, Constructivism, and Whole Language}

While the idea that more explicit instruction is needed for students with severe learning problems is not unique to SRSD, it has created controversy in the context of constructivist and whole language movements in schools (cf. Harris \& Graham, 1994, 1996b, 1996c; Harris, Graham, \& Deshler, 1998). Constructivism is a philosophy about teaching and learning, rather than a specific teaching method or approach (for a more detailed discussion of constructivism and whole language, see Harris \& Graham, 1994; Harris \& Graham, 1996c). Constructivists see children as inherently active, self-regulating learners who construct knowledge in developmentally appropriate ways within a social context. Views of the child as passively responding to the environment and learning through directly internalizing knowledge given by others are rejected (though it would be difficult to find any learning theory today that would make such an argument). According to constructivism, real understanding occurrs only when children participate fully in learning, which results in deeper and richer understanding and use of knowledge, thus promoting access to and application of what has been learned.

Constructivists reject teaching discrete skills in a linear sequence, and the belief that mastery of basic skills is a necessary prerequisite to more advanced learning and higher order thinking. Learning is socially situated and enhanced in meaningful and authentic contexts. Teachers are encouraged to facilitate and assist the construction of knowledge rather than to explicitly provide knowledge and information (Harris \& Graham, 1996b, 1996c; Harris \& Pressley, 1991; Pressley \& Harris, 1998).

Difficulties arise in the translation of constructivist theory into practice, however, not only for students with severe learning problems, but for many of their peers as well. Some see the emphasis in constructivism on maintaining an authentic and meaningful learning environment as totally incompatible with providing the level of explicit instruction we argue is needed for some students to gain important skills, strategies, and knowledge that come more easily to others. Some constructivists have even argued that teaching is a dirty word; they believe that it is neither necessary nor desirable (and even harmful) to teach explicitly, provide direct explanation, or require practice (Harris \& Graham, 1994, 1996c). This belief has serious ramifications for students with special needs.

\section{Whole Language and the Process Approach to Writing}

Perhaps one of the best known applications of constructivism is whole language. While definitions and practices within whole language vary widely, one commonly held viewpoint is the rejection of explicit instruction. Some whole language advocates believe that through rich immersion in authentic learning experiences, children will come to learn all they need to know, and develop all of the skills and abilities they need, in due developmental time. Directly addressing areas in which children have difficulties is seen by some as "flogging" a child's weaknesses and ignoring her or his strengths (cf. Edelsky, Altwerger, \& Flores, 1991; Kronick, 1990; Manning \& Manning, 1995; Poplin, 1988; Pressley \& Harris, 1998). Learning to read and write is believed to occur "naturally" within such environments, much as learning to speak does in early childhood.

Little or no explicit, focused, or isolated instruction and practice in basic skills may occur, although skills are addressed within the context of meaningful learning activities (Edelsky et al., 1991). Parents and educators across the country, however, have voiced concerns about the number of children who have not learned to write effectively, whose handwriting is illegible and labored in the upper elementary 
grades, and whose spelling remains "inventive" long past the early grades (Smith, 1994; Willis, 1993).

\section{Writers' Workshop and the Process Approach}

For more than a decade we have worked to advance the process approach to writing, often referred to as Writers' Workshop, in our schools. In general, however, until the late 1980s a product-oriented model of writing instruction prevailed in American schools (Applebee et al., 1990; Harris \& Graham, 1992). In the product-oriented model, mechanics and grammar tended to be emphasized over content and process. Further, writing was given limited time and attention, and few activities pursued in classrooms required sustained writing. Students were taught little about the processes and strategies involved in writing, and little was done to promote their development. A great deal of learning to write was expected to occur by reading the work of others and independently determining how to create similar compositions. First drafts were often final drafts, read only by the teacher-who primarily marked errors in mechanics and assigned grades. The important roles that writing plays in learning and communicating were often neglected.

In the process approach, teachers create an environment where students have time not only to write, but to think and reflect upon what they are writing about. Instruction takes place in a supportive environment where students are encouraged to choose their own topics, help each other, and take risks. Students write for real purposes and for real audiences and are given opportunities for extended writing. Students learn to see writing as a process, and a first draft as a draft. Writing conferences, peer collaboration, mini-lessons, modeling, sharing, and classroom dialogue are all essential components of this approach. Students see writing as a process that is difficult and frustrating at times, yet also a challenging and enjoyable vehicle for learning and selfexpression (Atwell, 1987; Graves, 1985).

Although the process-writing approach is all the support that some students need to help them develop and come to own important writing skills, abilities, and strategies, many other students, including those with severe writing problems, need more (Graham \& Harris, 1994). Because instruction in process-writing classrooms often involves capitalizing on "teachable moments" and mini-lessons, students might not learn all they need to know about writing strategies and processes. Important strategies might not be introduced because "teachable moments" are overlooked or do not occur, and mini-lessons might not offer the extensive, explicit, and supported instruction students need to master important strategies and abilities.

We believe, and have data to support this belief (cf. Danoff, Harris, \& Graham, 1993; Graham \& Harris, 2003, MacArthur, Schwartz, Graham, Molloy, \& Harris, 1996), that SRSD fits well with the process approach to writing or Writers' Workshop, an approach often found in whole language programs and in schools and programs that have not adopted a whole language approach. Further, students in the upper elementary, middle, and secondary grades face increasing demands for strategic writing performance, both as a means of learning and as a way to express what has been learned. The number of writing genres in which students need expertise also increases. Integrating SRSD with the process approach to writing provides a proactive, effective, and more efficient means for addressing these issues.

\section{An Integrated Approach}

Although some have argued that the integration of SRSD and other instructional approaches that include explicit and supported instruction with whole language or writingprocess approaches is impossible and misguided, many teachers, schools, and communities are demonstrating otherwise (Harris \& Graham, 1996b, 1996c). As we have argued elsewhere (Harris \& Graham, 1996b; Harris \& Pressley, 1991), the challenges faced by students with special needs, and indeed by all of us today, are complex. When we treat competing viewpoints with thoughtfulness and respect, a powerful repertoire for teaching and learning can be developed. We are obviously not advocating for a return to a primarily skills-oriented, back-to-basics curriculum. Rather, we are arguing that explicit, focused, and at times isolated instruction needs to be provided to the extent needed by individual children. Explicitness and structure do not necessarily equate with isolated skills training, decontextualized learning of subskills, passive learning, or the gradual accruing of basic skills (Harris \& Graham, 1994). We believe that explicit, focused instruction must, however, be integrated into the larger literacy context. We note that many other constructivism or writing-process advocates agree with this point. Students' perceptions of what they are doing and why they are doing it, and of their teachers's intentions, are critical in this integration (Harris \& Graham, 1996b, 1996c).

Teachers and schools have coherently integrated meaningful forms of explicit, and sometimes isolated, instruction within a larger, constructivism-based approach (Smith, 1994; Willis, 1993). Ideally, such coherent, integrated instruction is based in learning communities that are educationally purposeful, open, just disciplined, caring, and celebrative. Teacher goals and actions in these learning communities are based on ongoing assessment that includes students' cognitive and metacognitive abilities, skills, knowledge, and prior experience, as well as their affective and behavioral strengths, needs and characteristics. Students are provided the level of support needed (from explicit instruction through guided discovery) to acquire skills, abilities, and strategies and to develop and enhance important 
affective and behavioral targets, such as motivation, adaptive attributions, and engagement. Teachers are responsive to and plan for individual needs and differences, and students are given the time they need to attain valued outcomes of education (Harris \& Graham, 1996b). Having shared our perspective on SRSD and an integrated approach to teaching and learning, we turn now to the data base for SRSD, and how SRSD is conducted in the classroom.

\section{SRSD: THE RESEARCH EVIDENCE}

Since 1985, more than 30 studies using the SRSD model of instruction in the area of writing have been reported, involving students from the elementary grades through high school. In many of these studies, instruction has been conducted by the special and general education teachers in their own classrooms, often as a part of writers' workshop (cf. Danoff, Harris, \& Graham, 1993; De La Paz, 1999, 2001; De La Paz \& Graham, 2001; MacArthur, Graham, Schwartz, \& Shafer, 1995; MacArthur, Schwartz, \& Graham, 1991; MacArthur, Schwartz, Graham, Molloy, \& Harris, 1996; Sexton, Harris, \& Graham, 1998). Teachers have been able to implement SRSD and have found SRSD acceptable and beneficial in their classrooms. Studies have been undertaken to determine the contributions of various components of the SRSD approach and the stages of instruction (Danoff, Harris, \& Graham, 1993; Graham \& Harris, 1989; Sawyer, Graham, \& Harris, 1992). Studies have also been conducted by researchers independent of Graham, Harris, and their colleagues (Albertson \& Billingsley, 1997; Collins, 1992; Tanhouser, 1994). The majority of SRSD research has involved writing; studies have also been conducted, however, in reading and math, and one group of elementary through high school teachers has applied SRSD to homework completion and organization for classes and the school day (Bednarczyk, 1991; Case, Harris, \& Graham, 1992; Harris, Bennof, 1992; Johnson, Graham, \& Harris, 1997; Mason, 2002).

SRSD research has resulted in the development of writing strategies (typically with the assistance of teachers and their students) for a variety of genres; these include personal narratives, story writing, persuasive essays, report writing, expository essays, and state writing tests. SRSD has resulted in significant and meaningful improvements in children's development of planning and revising strategies, including brainstorming, self-monitoring, reading for information and semantic webbing, generating and organizing writing content, advanced planning and dictation, revising with peers, and revising for both substance and mechanics (Harris \& Graham, 1996a).

SRSD has resulted in improvements in four main aspects of students' performance: quality of writing, knowledge of writing, approach to writing, and self-efficacy (Graham,
Harris, MacArthur, \& Schwartz, 1991; Harris \& Graham, 1999). Across a variety of strategies and genres, the quality, length, and structure of students' compositions have improved. Depending on the strategy taught, improvements have been documented in planning, revising, content, and mechanics. These improvements have been consistently maintained for the majority of students over time, with some students needing booster sessions for long-term maintenance, and students have shown generalization across settings, persons, and writing media. Improvements have been found with normally achieving students as well as students with LD, making this approach a good fit for inclusive classrooms (cf. Danoff et al., 1993; De La Paz, 1999; De La Paz, Owen, Harris, \& Graham, 2000; MacArthur et al., 1996). In some studies, improvements for students with LD have resulted in performance similar to that of their normally achieving peers (Danoff et al., 1993; De La Paz, 1999; Sawyer, Graham, \& Harris, 1992).

\section{SRSD: STAGES OF INSTRUCTION}

Six basic stages of instruction are used to introduce and develop the writing and self-regulation strategies in the SRSD approach. SRSD has been used successfully with entire classes, small groups, and in tutoring settings (Graham \& Harris, 2003). Throughout the stages, teachers and students collaborate on the acquisition, implementation, evaluation, and modification of these strategies. The stages are not meant to be followed in a cookbook fashion. Rather, they provide a general format and guidelines. The stages can be reordered, combined (in fact, most lessons include at least two stages), revisited, modified, or deleted to meet student and teacher needs. Further, the stages are meant to be recursive - if a concept or component is not mastered at a certain stage, students and teachers can revisit or continue that stage as they move on to others. Some stages may not be needed by all students. For example, some students might already have had the background knowledge needed to use the writing strategy and selfregulation processes, and may skip this stage or act as a resource for other students who need this stage.

Lessons typically run anywhere from 20 to 60 minutes (depending on grade level and class schedules) at least three times a week. In most of our work with teachers and students, instruction takes less time than teachers anticipate. In the elementary grades, 8 to 12,30 - to 40 -minute lessons have typically been what students need to complete the stages (further detail by grade and genre can be found in Graham \& Harris, 2003).

The stages of instruction represent merely the bare framework of instruction. Thus, we follow this description with discussion of critical characteristics of SRSD instruction and guidelines for evaluation of this process. Additional 
explanation and discussion of the self-regulation strategies, planning for SRSD instruction, these writing strategies, and other writing strategies, can be found in Harris and Graham (1996a). Detailed lesson plans for story writing and persuasive essay writing are offered on the Center for Accelerating Student Learning (CASL) Web site, under Outreach, at www.vanderbilt.edu/CASL. In addition, all of the stages of instruction can be seen in both elementary and middle school classrooms in the video, "Teaching students with learning disabilities: Using learning strategies" (ASCD, 2002).

Procedures for promoting maintenance and generalization are integrated throughout the stages of instruction in the SRSD model. These include: identifying opportunities to use the writing and/or self-regulation strategies in other classes or settings, discussing attempts to use the strategies at other times, reminding students to use the strategies at appropriate times, analyzing how these processes might need to be modified with other tasks and in new settings, and evaluating the success of these processes during and after instruction. It is helpful to involve others, including other teachers and parents, to prompt the use of the strategies at appropriate times in other settings. Booster sessions, where the strategies are reviewed and discussed and supported again if necessary, are very important for maintaining the strategies for most of the students we have worked with.

\section{Stage 1: Develop and Activate Background Knowledge}

During this stage, background knowledge and any preskills, such as vocabulary (terms like setting, character, and so on as appropriate), concepts, and so on, students need for learning and using the writing and self-regulation strategies are developed. Preskills and background knowledge should be developed enough to allow students to move into the next stages, and their development can continue into stages 2 and 3.

In addition, we frequently start the development of individualized self-statements here. Self-statements, also referred to as self-speech, are a powerful form of self-regulation (for greater detail on their development and role in self-regulation, see Harris \& Graham, 1996a). The teacher collaborates with students to develop statements relevant to writing and to students' individual needs and characteristics. For example, a student who tends to become frustrated and quit easily might think, "I can do this if I use my strategy and take my time." The teacher discusses with the students how the things they say to themselves can help them or hurt them, and students might share some of the self-speech they currently engage in when asked to write, and how it helps them or needs to be changed. Negative or ineffective selfstatements, such as, "I'm no good at this," or, "I hate writing," can be identified, and how they interfere with performance can be discussed.

\section{Stage 2: Discuss It}

During this stage, the teacher and students discuss the strategies to be learned, with the writing strategy being carefully explained. Each step in the writing strategy is explained, as are any mnemonics to be used. The significance and benefits of the writing and self-regulation strategies are established. The teacher and the students discuss how and when to use the strategies; laying the foundation for generalization can begin here, as this discussion should not be limited to the current classroom or task at hand. Opportunities to use the strategy in new situations or for different tasks should be identified. The importance of student effort in strategy mastery and use is strongly emphasized, in part to increase motivation and to help develop positive, adaptive attributions (I can do this because I know the "trick of it" - the strategy — and I am trying hard). The goals of the strategies instruction are discussed and determined. During this stage, students are asked to make a commitment to learn the writing and self-regulation strategies and to act as a collaborator in both learning and evaluating the strategies.

Often, the teacher and students will also examine each student's current level of performance on the targeted writing genre, by looking through the student's writing portfolio and evaluating works or focusing on one or two recent compositions (students can also be asked to write a type of composition, such as a persuasive essay, to provide such a baseline if necessary). Examining current levels of performance can help set the stage for strategies instruction, helping students see what they are doing now and what they can expect to do once they learn the strategies. Current performance should be examined in a positive, collaborative manner with the emphasis on the changes to come. Examining current performance does not have to be done if the teacher thinks it will have a negative effect.

If current performance is assessed, graphing of performance might also be introduced at this stage. Aspects of the strategies instruction or goals of the instruction can be graphed, for example, students might graph how many of the seven common parts of a story they had in their current work, and then graph later stories as they learn a story-writing strategy. Graphing is a powerful part of self-monitoring and helps set the stage for both further self-monitoring and goal setting. If desirable, more than one goal can be graphed; students might also graph the number of words written, or the number of "million dollar words" (good vocabulary words) in each composition.

\section{Stage 3: Model It}

The teacher or a peer models the composition strategy and selected types of self-instructions while writing an actual composition during this stage. Types of self-instructions that can be introduced here include problem definition 
(what is it I have to do here?), focusing attention and planning (I have to concentrate; first I need to . . . then . . . ), strategy-step statements (I need to write down my strategy reminder), self-evaluation and error correcting (have I used all my parts-oops, I missed one, better add it in), coping and self-control (I can handle this; go slow and take my time), and self-reinforcement (I like this ending!). All of these forms should not be introduced at once; rather, teachers should select types of statements and model statements specific to the needs and characteristics of their students.

It is important that the modeling be natural and enthusiastic and that the self-instructions have appropriate phrasing and inflection. The self-instructions modeled should be matched to the students' verbal style and language; while they will develop their own statements later, the modeled statements are critical in helping them do so. If students initially use prompts (we typically do), such as a graphic or chart listing the strategy steps or detailing a mnemonic, and a graphic organizer for writing, the model should use those also (examples can be found in the lesson plans on the CASL Web site mentioned earlier). The teacher can also set a goal for his or her composition, such as including all seven story parts, and evaluate the composition to see if the goal was met. Students can also be involved in the writing process by helping the model.

After self-regulation of the writing strategy has been modeled, the teacher and students should discuss the importance of the self-statements the model used as well as the goal setting and self-assessment. At this point, we typically have students begin to develop their own preferred self-instructions, recording them on paper (and often on bulletin boards). These self-instructions will be used in later stages; modeling, re-explanation, and further development of self-instructions can occur in later stages as needed. At this point, the teacher and students can also discuss the strategy steps and instructional components and collaboratively decide if any changes are needed to make the strategy more effective and efficient. This can also be discussed again in later stages. Generalization of the strategy to other tasks and settings can be discussed further at this point.

Teachers with whom we have worked have either creatively augmented live modeling or come up with alternatives. One teacher who was uncomfortable with modeling from memory or from notes when she first began strategy instruction came up with an innovative approach that worked well for her and her students. She worked out her modeling script, making sure she had all of the components, steps, and self-instructions she wished to model. She then put her selftalk on audio tape, reading from the script but speaking naturally and appropriately. She played this tape with her writing group, using the overhead projector to simultaneously plan for a composition. When the modeling of planning (using the strategy prompt and graphic organizer) was over, she and her students collaboratively wrote the actual composition, using the notes generated while modeling. In addition, teachers have successfully incorporated videotapes of peers who have already learned the strategy modeling their use of the writing and self-regulation strategies.

\section{Stage 4: Memorize It}

During this stage, students are required to memorize the steps in the composing strategy and the meaning of any mnemonics used either to represent the strategy steps or some part of the steps. The stage is particularly important for students who experience memory difficulties - as one of our students told us, "You can't use it if you can't remember it!" Some students may not need this stage, and thus may skip it. Memorization of the strategy can continue into the next stage, or be combined with the next stage. Students can paraphrase the strategy as long as the meaning remains intact. Students might also be asked to memorize one or more selfinstructions from the personal lists they have generated.

\section{Stage 5: Support It}

Much like scaffolding provides support as a building is built, teachers at this stage support, or "scaffold," students' strategy use. Additional self-regulation strategies, such as goal setting, self-monitoring, or self-reinforcement, can be discussed, determined, initiated, or expanded. These components help to support motivation, maintenance and generalization, and cognitive and affective change. During this stage, students employ the strategy, self-instructions, and other self-regulation procedures as they actually compose. For example, each story written with support can be added to the graph the student has started. Due to the support received, performance should be high. The teacher provides as much support and assistance as needed, and may write collaboratively for a time with any students who need this level of assistance. Challenging but doable initial goals are individually determined collaboratively by the teacher and studentall students do not have to have the same goals. Criterion levels can be gradually increased until final goals are met.

Prompts, interaction, and guidance are faded at a pace appropriate to individual students until effective strategies use is achieved; thus students will move through this stage at different rates. Throughout this stage, the students and teacher continue to plan for and initiate generalization and maintenance of the strategies. This stage typically is the longest of the six stages for students who have serious writing difficulties. Students need to be given adequate time and support to master the strategy.

\section{Stage 6: Independent Performance}

If students have not already made the transition to use of covert ("in your head") self-instructions, this is encouraged 
at this stage while students now use the strategy independently. Self-regulation procedures are continued, but some can be gradually faded as appropriate and as determined by the teacher and students. Plans for maintenance and generalization continue to be implemented, including booster sessions over time. The teacher and students collaboratively evaluate strategy effectiveness and performance.

\section{SRSD IN THE SECOND GRADE}

Observing primary elementary students with disabilities and others who struggle with writing learn and then generalize and maintain planning and writing strategies has been an exciting component of our research. The characteristics inherent in the stages of SRSD instruction permit flexibility in developing and implementing lessons for these writers. Following SRSD instruction, we have seen students' writing evolve from one-sentence responses to multisentence papers that include critical rhetorical elements. Two planning strategies, a story-writing strategy and a strategy for persuasive essays, were recently taught to second-grade students in one of the schools we work in. The effectiveness of SRSD instruction for young elementary students who are struggling with writing can be illustrated by examining instruction and writing performance of two of these students, Lakeisha and Malcolm. As will be seen, modifications in the order of the 6 stages presented were made with these students.

\section{POW Gives Power}

A three-step framework for planning and writing-POW: Pick my idea; Organize my notes; Write and Say more-was used to structure the writing process before, during, and after writing. The writing instructor started the first lesson by initiating a discussion with Lakeisha and Malcolm about the "power" of the POW strategy and how the "organize my notes" step in POW is used to write different types of papers. SRSD instruction began with story writing, a reading and writing genre familiar to young students.

\section{Once Upon a Time ...}

The story planning strategy, W-W-W, What=2, How $=2$, was taught in lessons that incorporated six stages for strategy acquisition-discuss it, develop preskills and background knowledge, model it, memorize it, support it, and independent performance. Procedures for developing selfinstructions, goal setting, self-monitoring, and self-reinforcement were imbedded in the lessons. Seven story parts are included in $\mathrm{W}-\mathrm{W}-\mathrm{W}, \mathrm{What}=2, \mathrm{How}=2$ (see Figure 1):

\section{Discuss It}

Lakeisha's and Malcolm's love of stories and storytelling became evident in the first lesson when W-W-W, What=2,

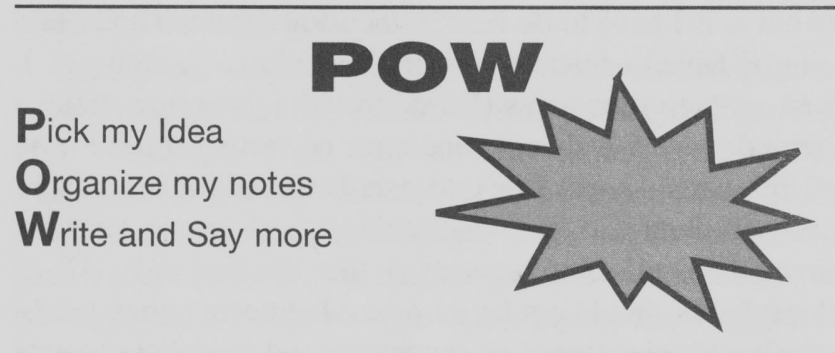

\section{W-W-W What $=2$ How $=2$}

Who is the main character?

When does the story take place?

Where does the story take place?

What does the main character do or want to do; what do other characters do?

What happens then? What happens with other characters?

How does the story end?

How does the main character feel; how do other characters feel?

\section{FIGURE 1 POW and $W-W-W$, What $=2$, How $=2$}

How $=2$ was introduced and discussed. The students eagerly applied their prior knowledge of story parts and story development to the strategy. Lakeisha, Malcolm, and the writing instructor read stories together, found story parts, and discussed how the story parts could be improved. Story parts were recorded on a graphic organizer (see Figure 2). To create a baseline for establishing writing goals, Lakeisha and Malcolm each read a story that they had previously written and charted the number of parts, out of the seven possible, included in this story on their rocket graphing sheet (see Figure 3) .

The difficulties that Lakeisha and Malcolm had demonstrated in the classroom with varying aspects of the writing process were reflected in the stories written prior to strategy instruction. Lakeisha had difficulties regulating the writing process and her emotions during writing. Her classroom teacher warned that any attempt to help Lakeisha could be met with uncontrollable tears. Malcolm had difficulty with the mechanics of writing. Malcolm's spelling and handwriting made it difficult for anyone to read what he had written. During the discussion stage, the writing instructor stressed that Lakeisha and Malcolm's future stories would include all seven story parts because they were going to learn the "trick" or strategy for writing "fun" stories that had all the parts. A goal was established to write a fun story with all 


\section{POW + W-W-W}

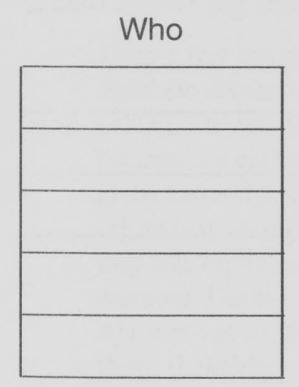

When

Where
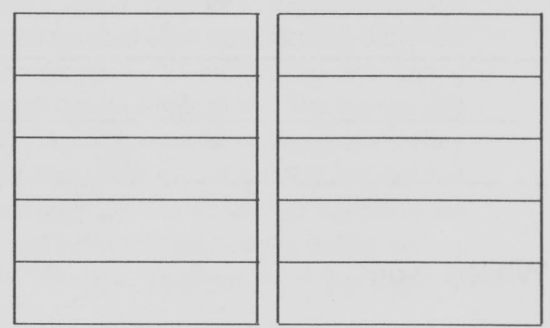

What

What
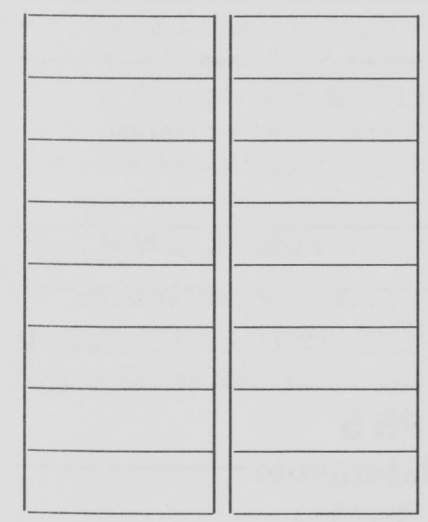

How

How
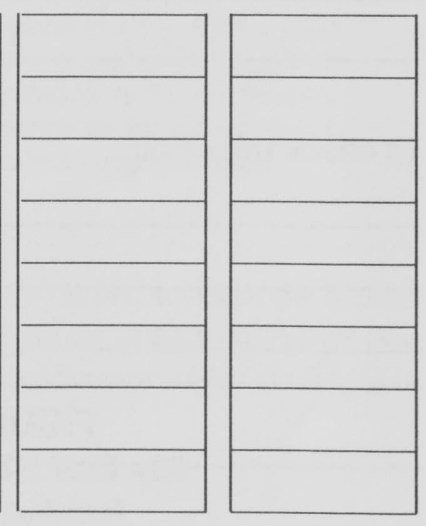

FIGURE 2

Graphic Organizer for Story Parts

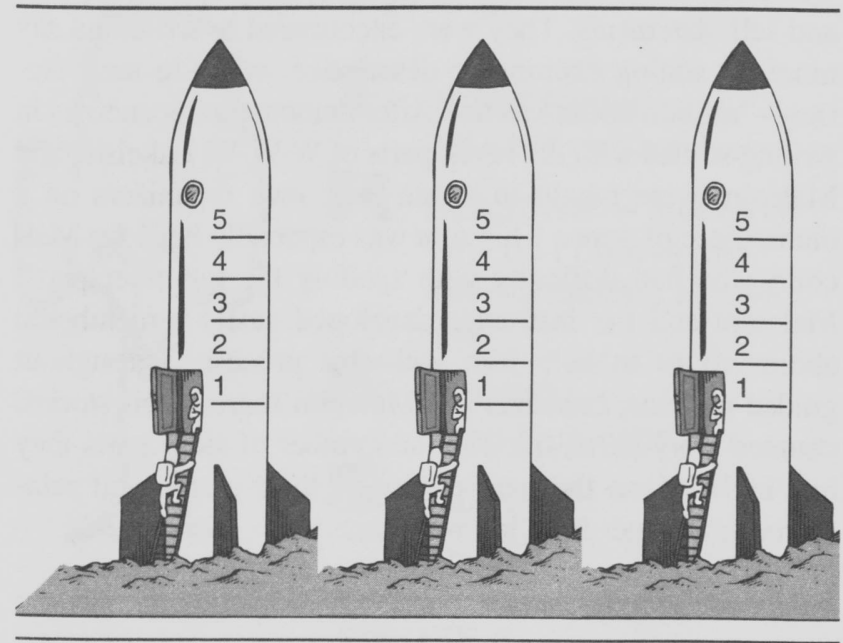

FIGURE 3

Essay Rockets seven parts next time. Lakeisha and Malcolm were told that they would be writing partners and would help each other by providing reminders to use POW $+\mathrm{W}-\mathrm{W}$-W during the writing lessons and in the classroom. In fact, they would get to report to the writing instructor situations in which they helped each other and any strategy use at home or school. The following stories were written prior to instruction:

The girl is looking at a egg. It have dots on it. It is hatching. She is looking down at the egg. (Lakeisha)

They are trying to cook something for lunch or dinner. (Malcolm)

\section{Develop Preskills and Background Knowledge}

Often in the initial stages of instruction a teacher may notice that students with weaker skills and language difficulties require more support with the vocabulary and concepts. Mini skill lessons, adding picture cues to instructional material, and providing additional practice can serve as modifications for developing skills for effective implementation of the strategy.

Lakeisha and Malcolm initially had difficulty with correctly applying the concepts. They were encouraged to look at the picture cues provided on practice cue cards (see Figure 4). Both students were able to independently discriminate between the meanings by the guided practice lessons.

\section{Model It}

During modeling, the instructor cognitively modeled (modeling out loud the steps and the thought processes of writing during all writing phases) using POW $+\mathrm{W}-\mathrm{W}-\mathrm{W}$ for story writing by including examples of how to set goals, self-monitor performance, and self-reinforce. During the modeling lesson, Lakeisha and Malcolm were allowed to give some ideas for the story, but the instructor was in charge of the writing process. Following the modeling lesson, the instructor, Lakeisha, and Malcolm discussed the things that were said while writing with POW + W-W-W. Lakeisha and Malcom developed and then recorded the things that they could say to themselves prior to, during, and after writing (see Figure 5). The instructor encouraged Lakeisha and Malcolm to develop statements, in their own words, which would help facilitate the writing process and success in using the strategies.

Lakeisha's self-statements directed her to remain positive and focused throughout the writing process- -I can do this; I will think about what I will do; Organize while I think; Do my best; I did my best." Malcolm's self-statements provided him with structure for the writing process and prompted him to be motivated during the process- - First, I need to pick an idea; I can think and write; I need to organize my notes; I can work my hardest; EXAMINE; I did a good job!" 


\begin{tabular}{|c|c|}
\hline \\
\hline What does the main \\
character do or want \\
to do; what do other \\
characters do?
\end{tabular} $\begin{gathered}\text { What happens then? } \\
\text { What happens with } \\
\text { other characters? }\end{gathered}$

FIGURE 4

Practice Cue Cards

\section{Memorize It}

Lakeisha and Malcolm began to memorize the W-W-W mnemonic and the meaning of the parts during the first lesson and continued to practice learning the strategy parts until they achieved fluency in orally describing the strategy. After strengthening her vocabulary skills, Lakeisha had no difficulty with memorizing the strategy. Malcolm, however, struggled with the memorization step. Lakeisha helped her partner by playing a card game with the practice cards prior to the start of each lesson.

\section{W-W-W What=2 How=2}

To think of good ideas:

While I work:

To check my work:

\section{FIGURE 5 \\ My Self Statements}

Support It

In order to scaffold instruction, the writing instructor, Lakeisha, and Malcolm collaboratively wrote a second story. This time the students were allowed to take more responsibility for story development. Two instructional segments followed collaborative writing. First, Lakeisha and Malcolm would plan and write their stories using the graphic organizer and self-statements. They were encouraged to write and say more by adding exciting or descriptive words to their stories- "million dollar words." After demonstrating success in writing stories with the seven parts of W-W-W, Lakeisha and Malcolm were taught to create their own organizers on a blank piece of paper. This step was especially hard for Malcolm who had difficulty with spelling the reminder parts. Malcolm and the instructor developed easily remembered abbreviations to help him with this process. Throughout guided practice, Lakeisha and Malcolm shared their stories, counted story parts, filled in the number of story parts they had included on the next rocket on their graph, and reinforced each other for a job well done.

\section{Independent Performance}

During independent practice, Lakeisha and Malcolm completed lessons that encouraged transfer of the POW + $\mathrm{W}-\mathrm{W}-\mathrm{W}$ strategy. These lessons included writing to a variety 
of story-prompt formats in diverse class settings. Lakeisha and Malcolm independently wrote the following seven-part stories following instruction:

\begin{abstract}
Once a boy named Cool $\mathbf{J}$ at 1:00 are at the home in New York. He scream loud because a bat was attacking him from behind. He was crying loud. His mother Aja was crying because she got attack too from behind too. The bat was still in the house flying. They both was sad not happy at all. They cry and cry all night long. Then the bat was kill one day and they was happy and happy the bat was kill. He was kill in the morning. The boy said to his mother, "Cool J and his mother Aja was not happy." So Aja, his sister, get a dog to guard them. (Lakeisha)
\end{abstract}

Once upon a time a boy and a girl were walking. Then they found a dog lost so then they tried to put him in a wagon but he was too big so he bought a bigger wagon so the dog could fit and it worked but he was too heavy. Then the dog got out of the wagon. Then the dog pulled them through the town. And they was outside. It was at 9:00. He wanted to play with him. He was happy because he had a dog. (Malcolm)

\section{That Is Why I Think . . .}

Lakeisha and Malcolm were excited to learn the second strategy, POW + TREE, for planning persuasive essays (see Figure 6). By this time they had become more confident in
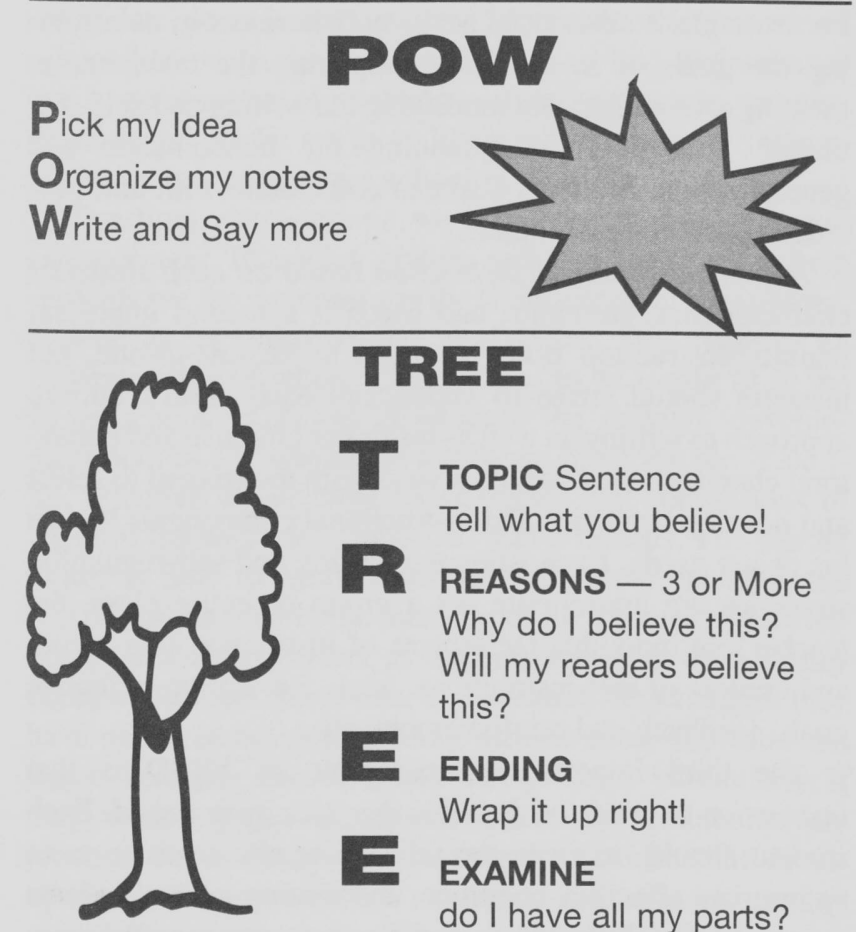

\section{TREE}

\section{TOPIC Sentence Tell what you believe! \\ F. REASONS - 3 or More Why do I believe this? Will my readers believe this?}

\section{ENDING}

Wrap it up right!

\section{EXAMINE}

do I have all my parts? their writing and more comfortable with the writing instructor. This was their first experience with persuasive writing, and they were eager to write papers that would tell the instructor their feelings about a topic. Lakeisha and Malcolm realized quickly that powerful persuasive essays could be written by using POW and by organizing notes using TREE. During discuss it, the instructor, Lakeisha, and Malcolm discussed POW + TREE while finding and recording the parts of TREE in persuasive essays.

Lakeisha recorded the number of parts of an essay (out of 5 possible: a topic sentence, three reasons, and an ending) she found in an essay that she had previously written. Malcolm, unfortunately, had responded to the essay prompt prior to instruction by simply recording the prompt sentence and was unable to use the graph. (We found that writing the prompt during pretest was not atypical for second-graders with disabilities.) The instructor again stressed that once the parts of TREE had been learned the rockets would be completed to the top, "busting" the rocket. Lakeisha wrote the following pretest essay:

\section{If you are about 9 and 10 you can pick out your own pet by yourself and a cat and a dog because they are big. (Lakeisha)}

Students who struggle with writing often have difficulties developing an organized thesis to present their arguments when writing persuasively. A list of transition words, therefore, was given to Lakeisha and Malcolm during the develop preskills and background knowledge stage. This list of simple transition words - first, second, third, fourth, next, then, also-helped Lakeisha and Malcolm focus attention on writing the parts in TREE in an organized manner when transferring ideas from the graphic organizer to the essay.

Following discussion and preskill development, the instructor cognitively modeled a persuasive essay using POW + TREE and a graphic organizer (see Figure 7). The instructor made a check mark at the end of the paper to indicate that she had "examined" the essay part. The instructor, Lakeisha, and Malcolm discussed the instructor's self-statements and updated their individual lists. Lakeisha and Malcolm memorized and learned to use the POW + TREE strategy within a few lessons. In fact, during support it less scaffolding was needed to support successful persuasive planning and writing. Transitioning from the organizer to writing their own notes was much easier because they had practiced this step before. As in the story writing lessons, independent performance was supported by transferring strategy use to a variety of writing prompts and instructional settings. Lakeisha and Malcolm wrote the following fivepart persuasive essays following instruction:

Yes I think kids should eat snack in the classroom. First, lunch is too short. Second, I get hungry in class. Third, I get thirsty in class. Fourth, I get hyper. Fifth, it helps kids to stay 


\section{POW + TREE}

TOPIC Sentence

Tell what you believe!

R. REASONS - 3 or More

Why do I believe this?

Will my readers believe this?

\section{ENDING}

Wrap it up right!

\section{EXAMINE}

Do I have all my parts?

Yes? No?

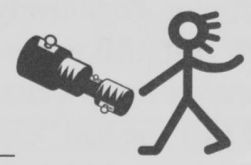

FIGURE 7

\section{POW + TREE Graphic Organizer}

awake. This is why I think kids should eat snacks in the classroom. (Lakeisha)

Teachers should ask children to write. First, they could have something to say. Second, you can have fun. Third, so you can listen. Fourth, so they can learn. That's why I think teachers ask children to write. (Malcolm)

Lakeisha and Malcolm were successful in improving the quality of their stories and persuasive essays as well as increasing the number of parts used and the number of words written. Following SRSD instruction, Lakeisha and Malcolm continued to support each other during classroom writing instruction. Their classroom teacher reported that their writing in the classroom had also improved and that she noticed a significant difference in the way that Lakeisha and Malcolm approached the writing process. Although Lakeisha and Malcolm have a lot to learn about the writing process, the strategies and self-regulation procedures they have cultivated will serve them well as they develop as writers.

\section{CHARACTERISTICS OF EFFECTIVE SRSD INSTRUCTION: IT'S NOT JUST WHAT YOU DO BUT HOW YOU DO IT}

Our work with teachers and students learning self-regulation and writing strategies has convinced us that how is every bit as important as what in strategy instruction. Teachers and students have helped us to identify several characteristics of the SRSD approach that are critical to effective implementation in schools and classrooms (Harris \& Graham, 1996a).

First, SRSD emphasizes collaborative learning among teachers and students. While the teacher initially provides the necessary degree of scaffolding or support, the responsibility for recruiting, executing, monitoring, evaluating, and modifying strategies is gradually transferred to the student. For example, students can act as collaborators in determining the goals of instruction; completing the task; implementing, evaluating, and modifying the writing and self-regulation strategies; and planning for maintenance and generalization. Students also can collaborate with and provide support for each other.

Individualization of instruction based on each student's characteristics, strengths, and needs is a second important feature. Instruction does not need to be one-to-one, but teachers should strive to understand each child's current approach to writing as well as his or her affective and behavioral characteristics, and then work with the student to select and develop strategies and instructional components that fit his or her needs. Even when the writing and self-regulation strategies are appropriate for a group or entire class, the teacher can individualize aspects of instruction (the nature and content of self-instructions, goals for writing, affective goals, feedback and reinforcement, etc.).

The third important characteristic of SRSD is that instruction is criterion based rather than time based. Each student should be given the time he or she needs to meet appropriate affective, cognitive, and writing goals. Students progress through the stages at their own pace, moving on as they are ready to do so. Thus, teachers do not plan to teach a writing strategy within a set period of time, and when they are working with groups, they may frequently shift among entire-group, smaller-group, and individual lessons. 
A fourth aspect teachers have found important is anticipation and planning for glitches-areas of instruction that might be difficult or problems that might arise. Teachers have found it helpful, before beginning instruction, to brainstorm things that could go wrong or prove difficult for some students, given what is known about the learners and the writing task. For example, some students (especially after third grade) may be resistant to using self-instructions out loud. Thus, the teacher might plan to describe it as "thinking out loud to yourself" and note that it can be done very quietly. If that doesn't work, teachers have allowed students to talk into a recorder as they work, or to read to themselves from their written statements. Students can collaborate in anticipating glitches as well. For example, maintenance and generalization can be challenging for some students. Together with the teacher, students can set a plan for booster sessions and prompts for generalizing.

Because teachers play such a critical role in helping students understand the meaning and efficacy of self-regulation and writing strategies, the fifth characteristic involves having enthusiastic teachers working within a support network. Enthusiastic, responsive teaching is an integral part of SRSD, as it is with all effective teaching. Given the complexity and demands of strategies instruction, a supportive network of teachers and administrators who can problem solve and share both successes and difficulties makes implementation considerably easier. Moreover, the impact of instruction on students is much greater, and maintenance and generalization of strategic performance across the curriculum and grades are more likely, when strategies instruction is embraced across a school or district.

The final characteristic we note here is developmental enhancement. To teach a strategy well, teachers need to help students see the meaning and the significance of the strategy, as well as its strengths and weaknesses. This requires an understanding of where the strategies to be taught fit in the larger scheme of things in terms of the students' development both as a writer and as a self-regulated learner. A skillful, effective writer employs strategies and conventions of the craft the way a jazz musician uses a melody. The mature writer is able to profit from the variations, the riffs, the twists, and ultimately the meaning of the strategies and conventions of writing. Thus, as students mature as writers, they continually refine, combine, and enhance the strategies they have mastered or created, using them in more sophisticated ways. Teachers can facilitate this process, particularly if they work together across the grades, by collaboratively planning for and supporting among their students the developmental enhancement of strategies and strategic performance (for examples, see Harris \& Graham, 1996a).

\section{EVALUATING SRSD INSTRUCTION}

Students who are taught a strategy that does not improve their performance certainly will not be enthusiastic about learning a second strategy. Ongoing assessment, rather than assessment only at the end of instruction, allows teachers and students to determine what is working and what changes need to be made. SRSD facilitates meaningful, ongoing assessment. The interactive, collaborative nature of the SRSD learning process allows teachers to assess changes in affect, behavior, and cognition. The following is an explanation of some basic principles for assessing SRSD methods and procedures. The list is certainly not exhaustive, but it provides a good starting point for effective evaluation.

\section{Involve Students as Coevaluators}

Students should be included as partners in the strategy evaluation process. Coevaluation not only increases students' sense of ownership and reinforces the progress they are making, but also provides teachers with much greater insight into the effectiveness of the strategies and SRSD instruction. Students can participate in many ways, such as learning to evaluate their writing based on their goals (selfassessment), or discussing with the teacher which components of instruction are most helpful to them or where they would recommend changes. Helping students ask appropriate self-questions (e.g., "Am I ready to move on to the next step?"; "Is this working for me?"; "Do I need to do anything differently?") is another effective way to help students evaluate their own progress. By asking students to share their reflections, teachers also gain valuable insight into their progress and readiness for moving on. Collaborative peer evaluation, such as peer-revising strategies (see Harris \& Graham, 1996a), is also a valuable component of the assessment process.

\section{Consider the Level of Evaluation Needed}

Strategies, methods, and procedures, such as W-W-W or TREE, that have been previously validated (both by research and by teachers in the classroom) typically need less scrutiny than a strategy being used for the first time. In other words, the amount of time and effort expended on assessing the usefulness of a strategy depends on the established validity of the strategy and a teacher's experience with it. However, it is important to remember that even well-validated strategies still need evaluation. At a minimum, teachers should know if (a) students are actually using the strategy, (b) usage of the strategy has a positive impact on performance and affective characteristics, and (c) students see the strategy as being valuable and manageable.

\section{Assess Changes in Performance, Attitudes, and Cognition}

Because the benefits of SRSD go beyond improving a student's performance, teachers should also look for changes in students' attitudes and cognitive processes. While teaching 
writing and self-regulation strategies, teachers might observe students for improvements in attitudes towards writing or confidence in their abilities. The teacher might also gather information about the amount and quality of writing the student does before and after SRSD instruction, or listen for spontaneous statements made about writing assignments. Open-ended questions - such as "What is good writing?" and "What do you most like to say to yourself while you write?"-can help provide insight. When evaluating performance, attitudes, and cognition, it is important to remember that some changes (e.g., reducing writing anxiety and improving attitudes) take more time than others to obtain.

\section{Assess While Instruction Is in Progress}

Often, classroom assessment occurs when teaching is "done." However, this is not a viable model for strategy instruction. Instead, assessment procedures need to reflect the developmental, dynamic, and ongoing process of learning to use a strategy.

\section{Assess How Students Actually Use the Strategy}

Over time, students will often modify a strategy or how they use it. As a result, it cannot be assumed that students are using the strategy as intended. Some modifications allow a strategy to meet a student's unique needs, but others (such as eliminating a necessary step) may not be useful or desirable. Teachers can monitor strategy usage directly by observing what students do as they write, asking questions, and discussing how things are working, or indirectly by looking for evidence of strategy usage in students' papers.

\section{Assess Students' Use of the Strategy Over Time and in New Situations}

We cannot assume that students will continue to use a particular strategy or successfully adapt a strategy to new situations. Therefore, it is beneficial to actively enhance maintenance and generalization of strategy usage from the very beginning of SRSD instruction. This might be done by periodically inviting students to explain the purpose of a strategy, or having students (and teachers) share ways they have used the strategy. A teacher might also ask students to keep a record of each time they use a strategy or how they modify it for other tasks. Ultimately, the goal is to determine if students need additional support to consistently apply the strategy in appropriate situations.

\section{Collaborate With Colleagues During the Evaluation Process}

If students are being taught a strategy that can be applied in different content areas or classrooms, it is important for teachers to involve colleagues in promoting this generalization and assessing whether the transition across subjects and settings is being made. It is also important to discuss with other teachers the strategy's effectiveness and whether it is appropriate in their classes, and, if not, how it could best be modified or what other strategies would be more useful. Working together in this way, teachers in different classes can provide reminders for students to use the strategy, help students with a particular aspect of the strategy as needed, or suggest modifications to make the strategy more effective for the present task.

\section{Use Portfolio Assessment Procedures}

Portfolio assessment is an ideal way to bring together many of the recommendations we have presented for SRSD evaluation. When students maintain portfolios, both teachers and students benefit. Students learn to engage in reflective self-evaluation, come to understand that development is as important as achievement (a major tenet of many process approaches to writing), and take greater responsibility for their own learning. Teachers gain new insights about assessment and teaching, and a greater understanding of their students' development and learning. Portfolio assessment does require that teachers establish the credibility of this approach with students and then become intimately involved in the maintenance and evaluation of student portfolios. Once teachers and students become comfortable with this form of assessment, positive results occur for both.

\section{A FEW FINAL TIPS FOR SRSD}

\section{Take It Slow}

For teachers just starting out with strategy instruction, we recommend starting slowly. It is tempting to try SRSD in the areas of instruction that present the greatest challenges or with students who are experiencing the most difficultly. However, despite good intentions, it is not fair to either party to take on too much too fast. Instead, begin with relatively simple strategies in an area where you are comfortable and anticipate success, and with students who are willing to learn the strategies. Although "nothing succeeds like success," initial failure can make persistence difficult for both teachers and students. Teachers can move on to greater challenges as they gain experience. We also recommend that strategies not be forced on students, but rather that they be offered to students.

\section{Take Advantage of Strategies Already Developed}

It is often easier to begin strategy instruction with an existing, already proven strategy, such as POW plus W-WW or POW plus TREE strategy presented in this article. Rather than attempting to create an effective strategy and become comfortable with the process of helping students master the strategy at the same time, teachers can take 
advantage of a strategy that has already been developed and validated (cf. Harris \& Graham, 1996a). Once the teacher and students are familiar with SRSD, then they can work together to create and evaluate new strategies, as they will often need to do to address their unique needs and situations.

\section{Learn Together}

If at all possible, teachers should collaborate with other teachers, as well as their students, while they learn to implement SRSD in the classroom. This professional collaboration allows teachers to share their personal triumphs and challenges with strategy instruction and serves to facilitate supportive feedback and problem solving.

\section{CONCLUSION}

Evaluations of SRSD by teachers and students have been positive, indicating sound social validity. One teacher, for example, commented how she could "see light bulbs going on" as her students learned to use writing strategies (Danoff et al., 1993, p. 315). One student proclaimed that SRSD should be "taught to all schools in the country" (Graham, Harris, \& Troia, 1998, p. 30), and another noted that "the WW-W strategy really builds up your resources." One student perhaps best described our goals for SRSD when he said, "Now this writing stuff makes sense!" When writing makes sense and children develop ownership of powerful self-regulation and writing strategies, every child can indeed write.

Harris and Graham have emphasized from the beginning, however, that SRSD should not be thought of as a panacea; promoting students' academic competence and literacy requires a complex integration of skills, strategies, processes, and attributes. However, by establishing affective, behavioral, and cognitive goals for instruction, SRSD represents an important contribution to teachers' instructional repertoires.

\section{REFERENCES}

Albertson, L., \& Billingsley, F. (1997, March). Improving young writers planning and reviewing skills while story-writing. Paper presented at the American Educational Research Association Conference, Chicago, IL

Applebee, A., Langer, J., Jenkins, L., Mullis, I., \& Foertsch, M. (1990). Learning to write in our nations' schools. Princeton, NJ: Educational Testing Service.

Applebee, A., Langer, J., \& Mullis, I. (1986). The writing report card: Writing achievement in American schools. Princeton, NJ: Educational Testing Service.

Applebee, A., Langer, J., Mullis, I., Latham, A., \& Gentile, C. (1994). NAEP 1992: Writing report card. Washington, DC: US Government Printing Office.

Association for Supervision and Curriculum Development (Producer). (2002). Teaching students with learning disabilities: Using learning strategies [Video]. (Available from ASCD, 1703 North Beauregard Street, Alexandria, VA 22311-1714).
Atwell, N. (1987). In the middle: Reading, writing, and learning from adolescents. Portsmouth, NH: Heinemann.

Bednarczyk, A. (1991). The effectiveness of story grammar instruction with a self-instructional strategy development framework for students with learning disabilities. Unpublished doctoral dissertation, University of Maryland, College Park.

Bereiter, C., \& Scardamalia, M. (1982). From conversation to composition: The role of instruction in a developmental process. In R. Glaser (Ed.), Advances in instructional psychology (Vol. 2, pp. 1-64). Hillsdale, NJ: Erlbaum.

Case, L. P., Harris, K. R., \& Graham, S. (1992). Improving the mathematical problem-solving skills of students with learning disabilities: Selfregulated strategy development. Journal of Special Education, 26, $1-19$

Collins, R. (1992). Narrative writing of option II students: The effects of combining the whole-language techniques, writing process approach and strategy training. Unpublished thesis, State University of New York, Buffalo.

Danoff, B., Harris, K. R., \& Graham, S. (1993). Incorporating strategy instruction within the writing process in the regular classroom: Effects in the writing of students with and without learning disabilities. Journal of Reading Behavior; 25, 295-322.

De La Paz, S. (1999). Teaching writing strategies and self-regulation procedures to middle school students with learning disabilities. Focus on Exceptional Children, 31, 1-16.

De La Paz, S. (2001). Teaching writing to students with attention deficit disorders and specific language impairment. Journal of Educational Research, 95, 37-47

De La Paz, S., \& Graham, S. (2001). Strategy instruction in planning. Enhancing the planning behavior and writing performance of middle school students. Manuscript submitted for publication.

De La Paz, S., Owen, B., Harris, K. R., \& Graham, S. (2000). Riding Elvis motorcycle: Using self-regulated strategy development to PLAN and WRITE for a state exam. Learning Disabilities Research and Practice, 15(2), 101-109.

Edelsky, C., Altwerger, B., \& Flores, B. (1991). Whole language: What's the difference? Portsmouth, NH: Heinemann.

Flower, L., \& Hayes, J. (1980). The dynamics of composing: Making plans and juggling constraints. In L. Gregg \& R. Steinberg (Eds.). Cognitive processes in writing (pp. 31-50). Hillsdale, NJ: Erlbaum.

Graham, S., \& Harris, K. R. (1989). Improving learning disabled students skills at composing essays: Self-instructional strategy training. Exceptional Children, 56, 201-216.

Graham, S., \& Harris, K. R. (1994). The role and development of self-regulation in the writing process. In D. Schunk \& B. Zimmerman (Eds.), Self-regulation of learning and performance: Issues and educational applications (pp. 203-228). New York: Lawrence Erlbaum.

Graham, S., \& Harris, K. R. (1996). Self-regulation and strategy instruction for students with writing and learning difficulties. In S. Ransdell \& M Levy (Eds.), Science of writing: Theories, methods, individual differences, and applications (pp. 347-360). New York: Lawrence Erlbaum.

Graham, S., \& Harris, K. R. (2000). The role of self-regulation and transcription skills in writing and writing development. Educational Psychologist, 35(1), 3-12.

Graham, S., \& Harris, K. R. (2002). Prevention and intervention for struggling writers. In M. Shinn, G. Stoner, \& H. Walker (Eds.), Interventions for academic and behavior problems II: Preventive and remedial approaches (pp. 589-610). Bethesda, MD: National Association of School Psychologists.

Graham, S., \& Harris, K. R. (2003). Students with learning disabilities and the process of writing: A meta-analysis of SRSD studies. In H. L. Swanson, K. R. Harris, \& S. Graham (Eds.), Handbook of learning disabilities (pp. 323-344). New York: Guilford Press.

Graham, S., Harris, K. R., \& Larsen, L. (2001). Prevention and intervention of writing difficulties with students with learning disabilities. Learning Disabilities Research and Practice, 16, 74-84.

Graham, S., Harris, K. R., MacArthur, C. A., \& Schwartz, S. (1991). Writ ing and writing instruction for students with learning disabilities: $\mathrm{Re}$ view of a research program. Learning Disability Quarterly, 14, 89-114. 
Graham, S., Harris, K. R., \& Reid, R. (1992). Developing self-regulated learners. Focus on Exceptional Children, 24(6), 1-16.

Graham, S., Harris, K. R., \& Troia, G. (1998). Writing and self-regulation: Cases from the self-regulated strategy development model. In D. Schunk \& B. Zimmerman (Eds.), Self-regulated learning: From teaching to self-reflective practices, (pp. 30). New York: Guilford.

Graves, D. (1985). All children can write. Learning Disability Focus, 1, $36-43$.

Harris, K. R. (1982). Cognitive-behavior modification: Application with exceptional students. Focus on Exceptional Children, 15(2), 1-16.

Harris, K. R. (1986). The effects of cognitive-behavior modification on private speech and task performance during problem solving among learning disabled and normally achieving children. Journal of Abnormal Child Psychology, 14, 63-76.

Harris, K. R., \& Alexander, P. A. (1998). Integrated, constructivist education: Challenge and reality. Educational Psychology Review, 10(2), $115-127$.

Harris, K. R., Bennof, A., Higdon, J., Liebow, H., Metheny, L., Nelson, V., Packman, S., \& Strouse, C. (1992). The Charles County Academic SelfManagement Consortium: SCOREing across the grades. Learning Disabilities Forum, 17, 37-42.

Harris, K. R., \& Graham, S. (1985). Improving learning disabled students' composition skills: Self-control strategy training. Learning Disability Quarterly, 8, 27-36.

Harris, K. R., \& Graham, S. (1992). Self-regulated strategy development: A part of the writing process. In M. Pressley, K. R. Harris, \& J. T. Guthrie (Eds.), Promoting academic competence and literacy in school (pp. 277-309). New York: Academic Press.

Harris, K. R., \& Graham, S. (1994). Constructivism: Principles, paradigms, and integration. The Journal of Special Education, 28, 233-247.

Harris, K. R., \& Graham, S. (1996a). Making the writing process work: Strategies for composition and self-regulation (2d ed.). Cambridge: Brookline Books.

Harris, K. R., \& Graham, S. (1996b). Memo to constructivists: Skills count, too. Educational Leadership, 53(5), 26-29.

Harris, K. R., \& Graham, S. (1996c). Constructivism and students with special needs: Issues in the classroom. Learning Disabilities Research and Practice, 11(3), 134-137.

Harris, K. R., \& Graham, S. (1999). Programmatic intervention research: Illustrations from the evolution of self-regulated strategy development. Learning Disability Quarterly, 22, 251-262.

Harris, K. R., Graham, S., \& Deshler, D. (Eds.). (1998). Advances in teaching and learning. Vol. 2: Teaching every child every day: Learning in diverse schools and classrooms. Cambridge: Brookline Books.

Harris, K. R., \& Pressley, M. (1991). The nature of cognitive strategy instruction: Interactive strategy construction. Exceptional Children, 57, 392-405.

Harris, K. R., Schmidt, T., \& Graham, S. (1998). Every child can write: Strategies for composition and self-regulation in the writing process. In K. R. Harris, S. Graham, \& D. Deshler (Eds.), Advances in teaching and learning. Vol. 2: Teaching every child every day: Learning in diverse schools and classrooms (pp. 131-167). Cambridge: Brookline Books.

Johnson, L., Graham, S., \& Harris, K. R. (1997). The effects of goal setting and self-instruction on learning a reading comprehension strategy among students with learning disabilities. Journal of Learning Disabilities, 30(1), 80-91.
Kendall, P., \& Braswell, L. (1982). On cognitive-behavioral assessment: Model, measures, and madness. In C. Speilberger \& J. Butcher (Eds.), Advances in personality assessment, (Vol. 1, pp. 35-82). Hillsdale, NJ: Erlbaum.

Kronick, D. (1990). Holism and empiricism as complementary paradigms. Journal of Learning Disabilities, 23, 5-8, 10.

MacArthur, C. A., Graham, S., Schwartz, S., \& Shafer, W. (1995). Evaluation of a writing instruction model that integrated a process approach, strategy instruction, and word processing. Learning Disability Quarterly, 18, 278-291.

MacArthur, C. A., Schwartz, S., \& Graham, S. (1991). Effects of a reciprocal peer revision strategy in special education classrooms. Learning Disabilities Research and Practice, 6, 201-210.

MacArthur, C., Schwartz, S., Graham, S., Molloy, D., \& Harris, K. R. (1996). Integration of strategy instruction into a whole language classroom: A case study. Learning Disabilities Research \& Practice, 11, $168-176$.

Manning, M., \& Manning, G. (1995). Whole language: They say, you say. Teaching PreK-8, 25, 50-55.

Mason, L. H. (2002). Self-regulated strategy instruction: Effects on expository reading comprehension among students who struggle with reading. Unpublished doctoral dissertation, University of Maryland, College Park.

Poplin, M. S. (1988). Holistic/constructivist principles of the teaching/ learning process: Implications for the field of learning disabilities. Journal of Learning Disabilities, 21, 389-400.

Pressley, M., \& Harris, K. R. (1998). Constructivism and instruction. Issues in Education: Contributions from Educational Psychology, 3(2), 245-255.

Sawyer, R. J., Graham, S., \& Harris, K. R. (1992). Direct teaching, strategy instruction, and strategy instruction with explicit self-regulation: Effects on learning disabled students' composition skills and self-efficacy. Journal of Educational Psychology, 84, 340-352.

Scardamalia, M., \& Bereiter, C. (1986). Written composition. In M. Wittrock (Ed.), Handbook of research on teaching (3rd ed., pp. 778-803). New York: MacMillan.

Scheid, K. (1991). Effective writing instruction for students with learning problems. Columbus, $\mathrm{OH}$ : LINC Resources.

Sexton, M., Harris, K. R., \& Graham, S. (1998). Self-regulated strategy development and the writing process: Effects on essay writing and attributions. Exceptional Children, 64(3), 295-311.

Smith, C. B. (Moderator). (1994). Whole language: The debate. Bloomington, IN: ERIC.

Tanhouser, S. (1994). Function over form: The relative efficacy of selfinstructional strategy training alone and with procedural facilitation for adolescents with learning disabilities. Unpublished doctoral dissertation, Johns Hopkins University, Maryland.

Willis, S. (November, 1993), "Whole language in the io's." ASCD Update, 35(9), 1-8..

Wong, B., Harris, K. R., Graham, S., \& Butler, D. L. (2003). Cognitive strategies instruction research in learning disabilities. In H. L. Swanson, K. R. Harris, \& S. Graham (Eds.), Handbook of learning disabilities (pp. 383-402). New York: Guilford Press. 